\title{
STRUCTURAL AND OPTICAL \\ CHARACTERIZATION OF ZINC OXIDE \\ FILMS PREPARED BY TWO STAGE; SPIN \\ COATING AND HYDROTHERMAL PROCESS
}

\section{Laxmi Dangol and Leela Pradhan Joshi}

Journal of Institute of Science and Technology

Volume 21, Issue 1, August 2016

ISSN: 2469-9062 (print), 2467-9240(e)

Editors:

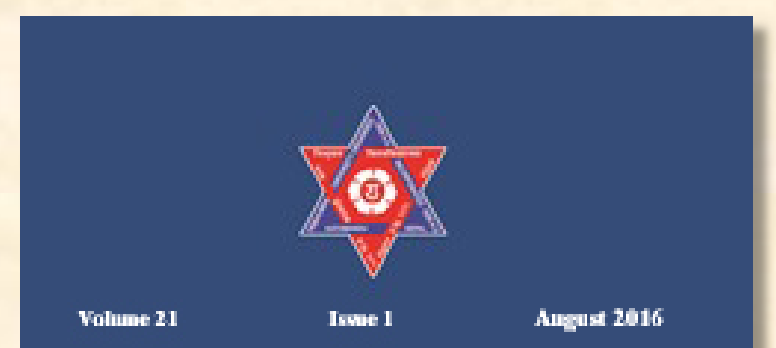

JOURNAL OF INSTITUTE OF

SCIENCE AND TECHNOLOGY

Prof. Dr. Kumar Sapkota

Prof. Dr. Armila Rajbhandari

Assoc. Prof. Dr. Gopi Chandra Kaphle

JIST, 21 (1), 61-64 (2016)

Published by:

Institute of Science and Technology

Tribhuvan University

Kirtipur, Kathmandu, Nepal 


\title{
STRUCTURAL AND OPTICAL CHARACTERIZATION OF ZINC OXIDE FILMS PREPARED BY TWO STAGE; SPIN COATING AND HYDROTHERMAL PROCESS
}

\author{
Laxmi Dangol, and Leela Pradhan Joshi* \\ Physics Department, Amrit Science Campus, Tribhuvan University, Kathmandu, Nepal \\ *Corresponding email: leela.pradhan@gmail.com
}

\begin{abstract}
Thin films of Zinc Oxide $(\mathrm{ZnO})$ of average thickness $364 \mathrm{~nm}$ were deposited on glass substrates via hydrothermal process using a mixture of $25 \mathrm{mM}$ aqueous solutions of zinc nitrate and hexamethylenetetramine at a constant temperature of $75 \pm 5^{\circ} \mathrm{C}$. The structure of $\mathrm{ZnO}$ film was analyzed by using X-ray diffraction (XRD). Our result showed that $\mathrm{ZnO}$ film is of polycrystalline nature with preferential orientation along (002) perpendicular to the substrate. Average crystallite size of prepared $\mathrm{ZnO}$ film was found to be $18 \mathrm{~nm}$. The Scanning Electron Microscope (SEM) image clearly showed the growth of nano-plate structure with an average thickness and breadth of $90 \mathrm{~nm}$ and $390 \mathrm{~nm}$ respectively. The band gap of $\mathrm{ZnO}$ was determined from transmittance spectrum captured in the visible wavelength. The calculated value of direct band gap was $3.24 \mathrm{eV}$.
\end{abstract}

Keywords: Thin film, Zinc oxide, Band gap, XRD, SEM

\section{INTRODUCTION}

Thin films of binary compound zinc oxide $(\mathrm{ZnO})$ have potential in the fabrication of future generation nanoscale electronic and optoelectronic devices due to possession of high transmittance in the visible range and high absorption coefficient (Benny et al. 2006). Generally $\mathrm{ZnO}$ exists as n-type wide band gap semiconductor which possesses greater mechanical and chemical strength. $\mathrm{ZnO}$ with various morphology such as nanorods, nanowires, nanoflakes are of great interest for the design of new generation dye-sensitized solar cells (Baxter \& Aydil 2006). ZnO has also been used in the large number of applications such as thin film transistors, gas sensors, plaster material in medicine (Alver et al. 2007, Xiaodan et al. 2007, Agnieszka \& Tcofil 2014). Its electrical, structural and optical properties can be modified by doping with elements such as Al, Mn, In (Shrestha et al. 2010, Yoshino et al. 2007, Ilican et al. 2007).

The synthesis of high quality $\mathrm{ZnO}$ thin film is very important for the development of numerous optoelectronic devices. Several efficient methods such as spray pyrolysis (Gomez-Pozos et al. 2007), chemical bath deposition (Cao \& Cai 2008), spin coating ( $\mathrm{Xu}$ et al. 2006), reactive magnetron sputtering (Li \& Wang 2009), and dip coating (Djouadi et al. 2009) are widely used to prepare good thin films of $\mathrm{ZnO}$. According to the application desired of $\mathrm{ZnO}$ thin films, we have prepared $\mathrm{ZnO}$ thin films using a cost effective hydrothermal process at mild conditions of low temperature, atmospheric pressure as well as allowing for the tuning of the band gap of $\mathrm{ZnO}$ film via changes in the thickness of seed layer. We adopted two step, spin coating and hydrothermal method to prepare thin film of $\mathrm{ZnO}$ as described by Zhang et al. in 2012. The structural, morphology and optical properties of prepared samples were investigated using X-ray Diffraction, Scanning Electron Microscope and Ultra-violet Visible spectrophotometer.

\section{MATERIALS AND METHODS}

First of all, a thin seed layer of Al doped Zinc Oxide (AZO) was deposited on a glass substrate using a spin coating method from a $0.3 \mathrm{M}$ precursor solutions of Zinc Acetate (analytical grade Merck 99\%) ethanol with diethanolamine (Shrestha et al. 2010). The hexahydrated Aluminum Chloride was added into the solution for $\mathrm{Al}$ doping. The $\mathrm{Al}$ doping percentage used here was of $2 \%$. A homemade spin coater of about $3000 \mathrm{rpm}$ and spinning time of 30 seconds per coat was used during preparation of the AZO film. The spin coated layer was then heated at $100 \pm 5^{\circ} \mathrm{C}$ for 10 minutes for soft baking followed by high heating at $400 \pm 5^{\circ} \mathrm{C}$ for 15 minutes in 
each coat. Ultimately, the samples were annealed at $400 \pm 5^{\circ} \mathrm{C}$ for another 30 minutes. These AZO substrates were then dipped into the aqueous mixtures of $25 \mathrm{mM}$ Zinc Nitrate and hexamethylentetratamine solution for 2 hours at constant temperatures of $75 \pm 5{ }^{\circ} \mathrm{C}$ to facilitate the growth of zinc oxide nanostructure via hydrothermal process (Zhang et al. 2012). Finally, the samples were rinsed with distilled water several times and annealed at $400^{\circ} \mathrm{C}$ in air for 30 minutes to remove any residues. The structural investigation of prepared film (sample C8) was performed using X-ray diffraction. The surface morphology of prepared film was studied by scanning electron microscope. Additionally, the effect of thickness of AZO coating on band gap of $\mathrm{ZnO}$ was also studied. For this experiment we prepared samples with different number of AZO coatings on glass substrates and band gaps were measured using the transmittance data measured using an Ocean Optics, USB 2000 spectrophotometer, Singapore.

\section{RESULTS AND DISCUSSION}

Fig. 1 shows the $\mathrm{X}$-ray diffraction pattern of $\mathrm{ZnO}$ thin film grown on glass substrate at $75 \pm 5^{\circ} \mathrm{C}$ (sample C8) using a conventional hydrothermal process. The X-ray scan was run in the $2 \theta$ range of $10^{\circ}$ to $81^{\circ}$. It shows three prominent peaks at $2 \theta=$ $32.80^{\circ}, 35.49^{\circ}$ and $37.28^{\circ}$. The strong peak observed at $2 \theta=35.49^{\circ}$ corresponds to $\mathrm{d}=2.52 \AA$ shows the orientation of (002) planes. Other two peaks at $2 \theta=32.80^{\circ}(\mathrm{d}=2.72 \AA)$, and $2 \theta=37.28^{\circ}$ $(\mathrm{d}=2.40 \AA)$ shows the $(\mathrm{hkl})$ plane orientation along (100), and (101) respectively. Other small intensity peaks are observed at $2 \theta=48.57^{\circ}(\mathrm{d}=1.87 \AA), 2 \theta=$ $57.58^{\circ}(\mathrm{d}=1.59 \AA)$ and $2 \theta=63.87^{\circ}(\mathrm{d}=1.45 \AA)$ which show orientation along (102), (110) and (103) planes respectively. The indexing of (hkl) planes were made with reference to JCPDS card no. 361451 (Shrestha et al. 2010). The c-axis lattice constant of the $\mathrm{ZnO}$ thin film was calculated to be of $5.21 \AA$. The XRD pattern of the film shows that the $\mathrm{ZnO}$ film is polycrystalline hexagonal system. The crystallite size D, was estimated using Debye Scherrer's formula, $D=0.9 \lambda / \beta \cos \theta$ where $\lambda$ is the $\mathrm{X}$-ray wavelength and $\beta$ measures the full width half maximum (FWHM) of the peak and $\theta$ is the braggs angle respectively (Shakti 2010). The average crystallite size was estimated by consideration of FWHMs of first three major peaks of Fig. 1 which is found to be about $18 \mathrm{~nm}$.

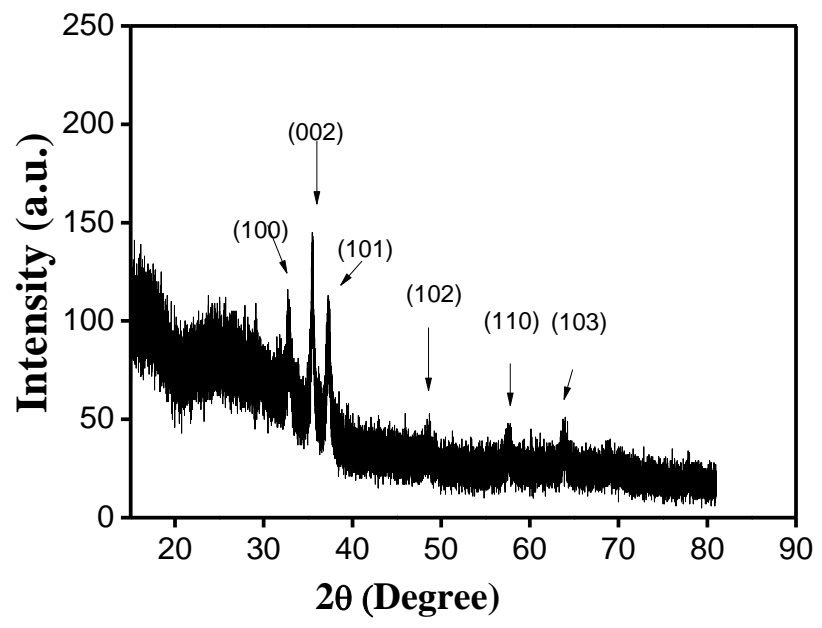

Fig.1. X-ray diffraction pattern of $\mathrm{ZnO}$ film grown on glass substrate at $75 \pm 5^{\circ} \mathrm{C}$ (sample C8).

Fig. 2 shows the scanning electron microscope image of $\mathrm{ZnO}$ film grown on glass substrate at $75 \pm$ $5^{\circ} \mathrm{C}$. It clearly shows the growth of nano-plates of $\mathrm{ZnO}$ film. The average thickness and breath of these sheets were estimated, according to the scale bar provided at the bottom of image, to be $90 \mathrm{~nm}$ and $390 \mathrm{~nm}$ respectively.

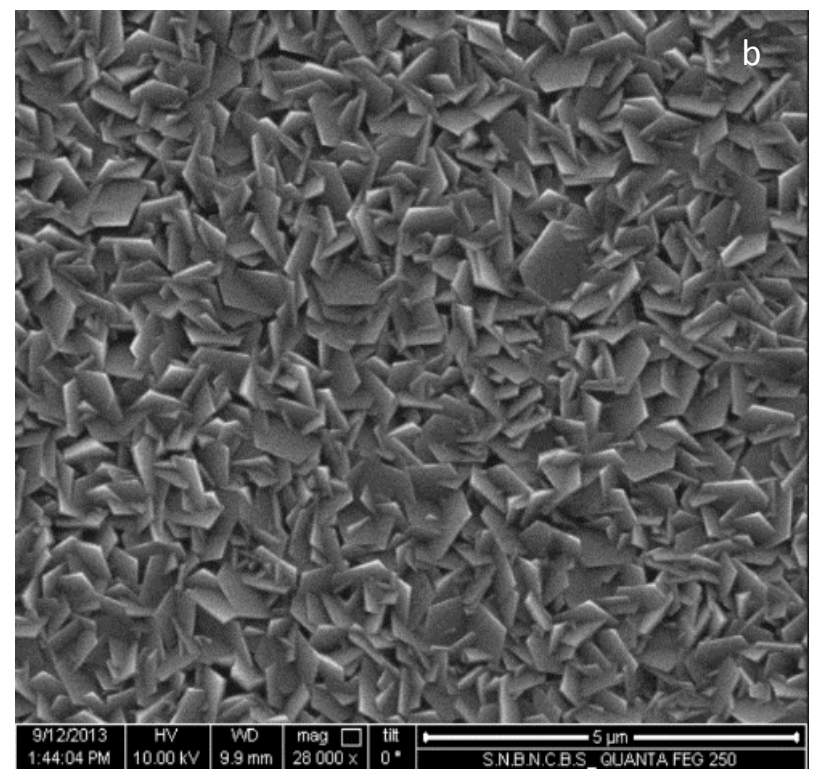

\section{Fig. 2. Scanning Electron Microscope image of $\mathrm{ZnO}$ thin film prepared on glass at $75 \pm 5^{\circ} \mathrm{C}$ (sample C8).}

Fig. 3 shows the recorded optical transmittance spectrum of $\mathrm{ZnO}$ thin film in the wavelength range from $300 \mathrm{~nm}$ to $1000 \mathrm{~nm}$. The maximum transmission of the film was more than $80 \%$ in the visible range with a sharp cut-off at approximately $380 \mathrm{~nm}$. 

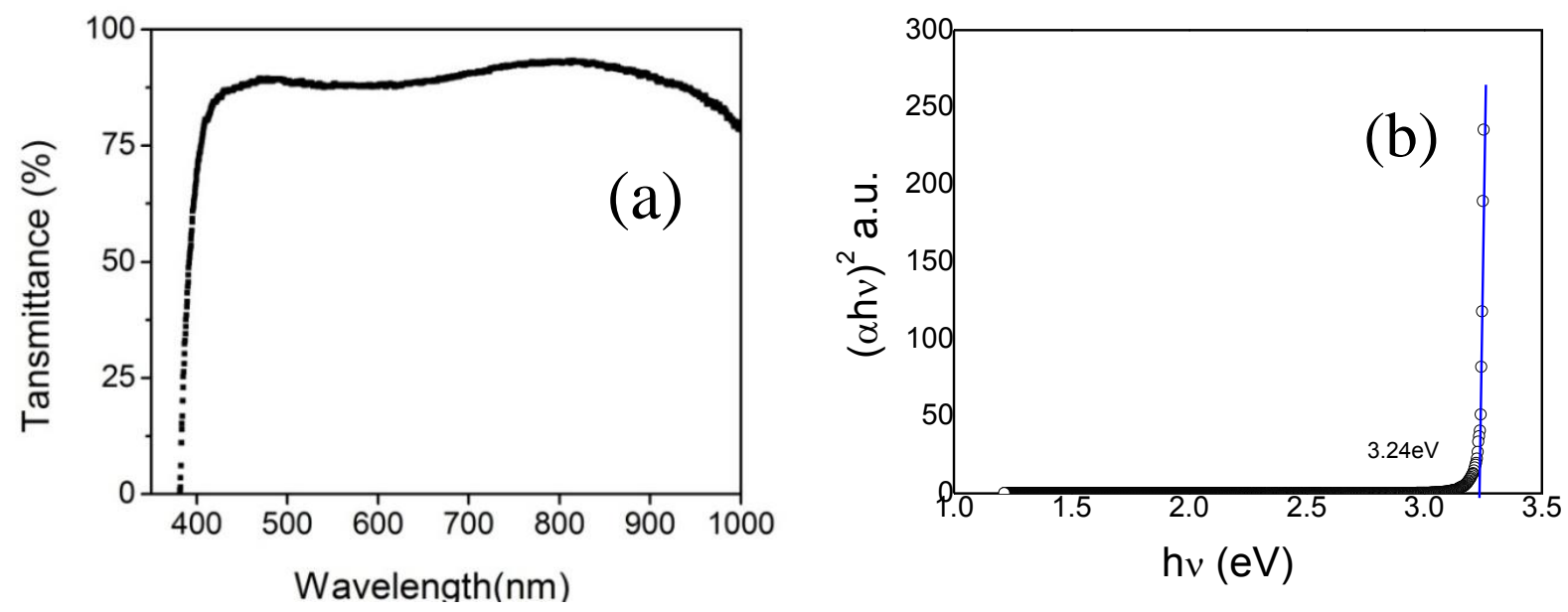

Fig. 3. (a) Transmission spectrum (b) corresponding (ahv) ${ }^{2}$ versus hv plot of ZnO film grown on glass substrate at $75 \pm 5^{\circ} \mathrm{C}$ (sample C8).

The thickness (t) of the film was calculated using the swanepoel method (Dorranlan et al. 2012) for which $t$ is given by:

$$
t=\frac{\lambda_{1} \lambda_{2}}{2\left[n_{1}\left(\lambda_{1}\right) \lambda_{2}-n_{2}\left(\lambda_{2}\right) \lambda_{1}\right]}
$$

where $\mathrm{n}_{1}$ and $\mathrm{n}_{2}$ are the refractive indices at wavelengths $\lambda_{1}$ and $\lambda_{2}$ respectively. Using the transmittance of adjacent maxima and minima observed in the spectrum, $\mathrm{n}_{1}$ and $\mathrm{n}_{2}$ were calculated as described by (Dorranlan et al. 2012). The average calculated value of film thickness using above equation is found to be about $364 \mathrm{~nm}$. We calculated the direct band gap of prepared $\mathrm{ZnO}$ film by extrapolating the linear portion of the curve of $(\alpha h v)^{2}$ versus $h v$ on $x$-axis. The direct band gap of $\mathrm{ZnO}$ is obtained using the equation

$$
(\alpha h v)^{2}=A\left(h v-E_{g}\right)
$$

where $\alpha, \mathrm{h} v, \mathrm{E}_{\mathrm{g}}$ and $\mathrm{A}$ represent the absorption coefficient, photon energy, band gap, and a constant respectively (Joshi et al. 2015). The calculated value of band gap from above curve (Fig. 3b) after extrapolation of the linear portion of the curve of sample $\mathrm{C} 8$ is $\mathrm{Eg}=3.24 \mathrm{eV}$. Here, in this report we have also studied the effect of thickness of seed layer of AZO on band gap of $\mathrm{ZnO}$ growth in hydrothermal process. Fig. 4 shows the graphs of $\mathrm{ZnO}$ films prepared from same molar concentration of growth solution but with different number of coats of seed layer of AZO film on glass substrate. The samples made from 3 coats and 4 coats of seed layer were named as S3 and S13 respectively. The results showed that as we increase the thickness of seed layer in the growth of $\mathrm{ZnO}$ film the band gap only ranges from $3.22 \mathrm{eV}$ to 3.24 $\mathrm{eV}$ (shown in Table 1 below).

Table 1. The seed layer thickness, concentrations of zinc acetate and growth solution, and band gap of $\mathrm{ZnO}$.

\begin{tabular}{|c|c|c|c|c|c|c|}
\hline $\begin{array}{c}\text { S. } \\
\text { No. }\end{array}$ & $\begin{array}{c}\text { Sample } \\
\text { Name }\end{array}$ & $\begin{array}{c}\text { No. of } \\
\text { coats }\end{array}$ & $\begin{array}{c}\text { Precursor Solution } \\
\text { Concentration (M) }\end{array}$ & $\begin{array}{c}\text { Al doping } \\
\text { (at. \%) }\end{array}$ & $\begin{array}{c}\text { Growth } \\
\text { Concentration (mM) }\end{array}$ & Band gap (eV) \\
\hline 1 & S3 & 2 & 0.3 & 2 & 25 & 3.22 \\
\hline 2 & C8 & 3 & 0.3 & 2 & 25 & 3.24 \\
\hline 3 & S13 & 4 & 0.3 & 2 & 25 & 3.21 \\
\hline
\end{tabular}

The estimated band gap of $\mathrm{ZnO}$ films from 2, 3, and 4 coatings of seed layer were $3.22 \mathrm{eV}, 3.24 \mathrm{eV}$, and $3.21 \mathrm{eV}$ respectively. It showed no significant change in band gap of $\mathrm{ZnO}$ for changing the number of coats of seed layers prior to grow $\mathrm{ZnO}$ film in hydrothermal process. 


\section{CONCLUSIONS}

Thin films of zinc oxide were prepared using a hydrothermal process from a spin coated seed layers of Al doped zinc oxide. The SEM image shows nanoplate structure of $\mathrm{ZnO}$. The average thickness and breadth of these plates of $\mathrm{ZnO}$ were found to be of about $90 \mathrm{~nm}$ and $390 \mathrm{~nm}$ respectively. The X-ray diffraction result showed the $\mathrm{ZnO}$ film's polycrystalline nature with (002) preferential orientation. The crystallite size was estimated to be 18 $\mathrm{nm}$. Optical transmission data captured in the visible wavelength range shows band gap of hydrothermally grown $\mathrm{ZnO}$ films with 3 coats of AZO seed layer was found to be of about $3.24 \mathrm{eV}$. The study on effect of number of coatings of seed layer on band gap of $\mathrm{ZnO}$ film developed by hydrothermal process shows no significant change.

\section{ACKNOWLEDGEMENTS}

The work was partly supported by University Grants Commission, Sanothimi, Bhaktpur, Nepal.

\section{REFERENCES}

Agnieszka, K. R. and Tcofil, J. 2014. Zinc Oxide From Synthesis to Application: A Review. Materials 7: 2833.

Alver, U., Kılınç, T., Bacaksız, E., Küçükömeroǵlu, T., Nezir, S., Mutlu, İ. H. and Aslan, F. 2007. Synthesis and characterization of spray pyrolysis zinc oxide microrods. Thin Solid Films 515: 3448

Baxter, J. B. and Aydil, E. S. 2006. Dye-sensitized solar cells based on semiconductor morphologies with $\mathrm{ZnO}$ nanowires. Solar Energy Materials \& Solar Cells, 90: 607.

Benny, J., Manoj, P. K. and Vaidyan, V. K. 2006. Studies on the structural, electrical and optical properties of Al-doped $\mathrm{ZnO}$ thin films prepared by chemical spray deposition. Ceramics International 32:487.

Cao, B. and Cai, W. 2008. From $\mathrm{ZnO}$ nanorods to nanoplates: chemical bath deposition growth and surface-related emissions. Journal of Physical Chemistry C, 112: 680.

Djouadi, D., Chelouche, A., Aksas, A. and Sebais, M. 2009. Optical properties of $\mathrm{ZnO} /$ silica nanocomposites prepared by sol-gel method and deposited by dip-coating technique. Physics Procedia, 2: 701.

Dorranlan, D., Dejam,L. and Mosayebian, G. 2012. Optical Characterization of $\mathrm{Cu}_{3} \mathrm{~N}$ Thin film with swanepoel method. Journal of Theoretical and Applied Physics, 6(13): 709.

Gomez-Pozos, H., Maldonado, A. and Olvera, M. de la L. 2007. Effect of the $[\mathrm{Al} / \mathrm{Zn}]$ ratio in the starting solution and deposition temperature on the physical properties of sprayed ZnO:Al thin films. Materials Letters, 61: 1460.

Ilican, S., Caglar, M. and Caglar, Y. 2007. Determination of the thickness and optical constants of transparent indium-doped $\mathrm{ZnO}$ thin films by the envelope method. Material Science-Poland, 2: 1.

Joshi, L. P., Subedi K. P., Dangol L., Shrestha, P. and Shrestha, S. P. 2015. Preparation and characterization of zinc oxide nanosheets for dye-sensitized solar cell using vitis vinifera dye extraction. Journal of Electrical and Electronics Engineering, 2(11):1.

Li, J. and Wang, Z. Y. 2009. Study of transparent conducting $\mathrm{ZnO}: \mathrm{Al}$ films deposited on organic substrate by reactive magnetron sputtering. Journal of Physics Conference Series, 152: 012053.

Shakti, N. 2010. Structural and Optical Properties of sol-gel prepared $\mathrm{ZnO}$ thin film. Applied Physics Research, 2(1):19.

Shrestha, S. P., Ghimire, R., Nakarmi, J. J., Kim, Y.-IS., Shrestha, S., Park, C.Y. and Boo J.H. 2010. Properties of $\mathrm{ZnO}$ :Al films prepared by spin coating of aged precursor solution. Bull Korean Chemistry Society, 31:1.

Xiaodan, Z., Hongbing, F., Ying, Z., Jian, S., Changchun, W. and Zhang, C. 2007. Fabrication of high hole - carrier density ptype $\mathrm{ZnO}$ thin films by $\mathrm{N}$-Al co-doping. Applied Surface Science, 253: 3825.

$\mathrm{Xu}$, Z. Q., Deng, H. Li, Y. Guo, Q.H. and Li, Y.R. 2006. Characteristics of Al-doped c-axis orientation $\mathrm{ZnO}$ thin films prepared by the sol-gel method. Materials Research Bulletin 41: 354 .

Yoshino, K., Oyama, S., Yoneta, M. and Taniyama, T. 2007. Structural and magnetic characterization of Mn-doped $\mathrm{ZnO}$ films grown by spray pyrolysis method. Materials Science and Engineering B 148: 234.

Zhang, Y., Ram, M. K., Stefanakos, E. K. and Goswami, D. Y. 2012. Synthesis, characterization, and applications of $\mathrm{ZnO}$ nanowires. Journal of Nanomaterials, Article ID 624520 . 